\title{
The Problem of the Unbridgeable Ontological Gap Between the Brain and Our Private Experiences in Wittgensteinian Terms
}

O problema da lacuna ontológica intransponível entre o cérebro e nossas experiências particulares em termos Wittgensteinianos

\author{
Nara M. Figueiredo \\ Postdoctoral Fellow \\ University of São Paulo [USP]
}

\section{RESUMO}

$\mathrm{O}$ artigo argumenta que a noção comum de que existe uma lacuna entre um escopo físico, a saber, processos cerebrais, e algo imaterial, como experiências privadas, é uma ilusão provocada pelos conflitos conceituais de nossa compreensão. A fim de superar essa ilusão, é necessário esclarecer os fundamentos e implicaçóes dos usos de conceitos-chave no campo cognitivo.

\section{PALAVRAS-CHAVE}

Expressão; Linguagem; Representação; Analogia; Experiência.

\begin{abstract}
The paper argues that the common notion that there is a gap between a physical scope, namely, brain processes, and something immaterial such as private experiences is an illusion provoked by the conceptual conflicts of our understanding. In order to overcome this illusion, it is necessary to clarify the foundations and implications of the uses of key concepts in the cognitive field.
\end{abstract}

\section{KEY WORDS}

Expression; Language; Representation; Analogy; Experience. 


\section{Introduction}

The nature of mental states and events is a very controversial topic in the cognitive sciences and it has led cognitive neuroscientists to several challenges when it comes to understanding the relation between private experiences and brain activity. I will defend that the idea that there is a gap between a physical scope, namely, brain processes, and something immaterial such as private experiences, — namely, feelings, perceptions, intentions emotions and so on - is an illusion provoked by the conceptual conflicts of our understanding. To overcome this illusion, we have to clarify the foundations and implications of the uses of key concepts in the cognitive field.

In this paper I will present six points with the overarching aim of persuading the reader that the very idea of a gap is a conceptual confusion. I will consider that the paper achieved its goals if, by understanding these points, the reader acknowledges their importance to the problem of the gap. The six points are: (I) the normative aspect of our expressions, (2) the private language argument, (3) the concept of representation as a relation (4) the non-explanatory role of the concept of representation (5) the beetle in the box analogy and (6) the necessity of experiences for our understanding.

These points are going to support my claim that the problem of the ontological gap is due to misunderstandings regarding our notions of epistemic privacy, private experiences, representation and content in the contexts of mind and brain investigations. In order to show this, I will address the notion of representation and why private states and events cannot represent, and refer to the normativity of the notions of content and representation and its non-explanatory role. My claim is justifiable based on Wittgenstein's private language argument and his beetle in a box analogy that show that whatever private experiences might be (the conscious what it is like), they cannot be taken as a reference of meaning and they are irrelevant for understanding the natural processes that we associate to them. Despite that, I will show that it is not irrelevant for us to have a first person understanding/experience, and it is not irrelevant that there are first person experiences. I later briefly discuss, in the concluding remarks, how we can defend a non-reductionist approach of the mind, that neither denies the existence of private experiences nor reduces them to their physical components. I suggest that these six points lead us to take the physical scope as an aspect of mental states or events, without supposing either a relation, or identification between brain activity and private experiences, for the nature of mind is expressed in our use of language and it is what we understand and define as mind.

\section{The normative aspect of our expressions}

Many of Wittgenstein's endeavors were to void the philosophical problems that lead us to a state of paralysis; the giddiness, as he says, characteristic of when we are facing paradoxes. The ontological gap between the brain and the conscious mind is mentioned by him as one of these cases. He focuses our attention on the fact that we set the framework of the paradox already when we say the sentence 'This is produced by a brain process!' aiming to point at our own conscious state. 
The feeling of an unbridgeable gulf between consciousness and brain process: how come that this plays no role in reflections of ordinary life? This idea of a difference in kind is accompanied by slight giddiness - which occurs when we are doing logical tricks. (The same giddiness attacks us when dealing with certain theorems in set theory.) When does this feeling occur in the present case? It is when I, for example, turn my attention in a particular way on to my own consciousness and, astonished, say to myself: "THIS is supposed to be produced by a process in the brain!" as it were clutching my forehead. - But what can it mean to speak of "turning my attention on to my own consciousness"? There is surely nothing more extraordinary than that there should be any such thing! What I described with these words (which are not used in this way in ordinary life) was an act of gazing. I gazed fixedly in front of me but not at any particular point or object. My eyes were wide open, brows not contracted (as they mostly are when I am interested in a particular object). No such interest preceded this gazing. My glance was vacant; or again, like that of someone admiring the illumination of the sky and drinking in the light. Note that the sentence which I uttered as a paradox ("THIs is produced by a brain process!") has nothing paradoxical about it. I could have said it in the course of an experiment whose purpose was to show that an effect of light which I see is produced by stimulation of a particular part of the brain. - But I did not utter the sentence in the surroundings in which it would have had an everyday and unparadoxical sense. And my attention was not such as would have been in keeping with that experiment. (If it had been, my gaze would have been intent, not vacant) (Wittgenstein, 2009, \$4I2).

This is one of many examples in which Wittgenstein points to the normative aspect of our language. In a Wittgensteinian perspective, intentional states are normatively constituted within linguistic, social practices (Cash, 2009). Normativity, or grammatical statements, is considered as opposed to empirical ones, which should be subject to truth conditions. This leads us to his to questions about the status of our statements about consciousness:

Is my having consciousness a fact of experience? - But doesn't one say that human beings have consciousness, and that trees or stones do not? - What would it be like if it were otherwise? - Would human beings all be unconscious? No; not in the ordinary sense of the word. But I, for instance, would not have consciousness as I now in fact have it (Wittgenstein, 2009, \$418).

Wittgenstein clarifies that the aim of these questions is merely to focus our attention on the basic statements that we make regarding simple facts. For example, 'I am here', 'This is a stone' or 'Apples are fruits.' "What we are supplying are really remarks on the natural history of human beings; not curiosities, however, but facts that no one has doubted, which have escaped notice only because they are always before our eyes" (ibid., p. 415). These statements exemplify the normativity of language, for, indubitable facts are not facts. They are public agreements of how we conceive things. They are not to be verified, but accepted. In this sense, it is not a matter of fact that private experiences are essentially private. Neither it is a matter of fact that our private experiences have content. For there are no means to verifying it. 
The idea we have that mental states are essentially private, is mainly due to uses of language similar to: 'Only I can feel my pain', "only you can know if you had that intention. One might tell someone this when explaining the meaning of the word "intention" to him. For then it means: that is how we use it. (And here "know" means that the expression of uncertainty is senseless.)" (Wittgenstein, 2009, \$247)

The idea that our private experiences have content is due to uses such as 'I see x', or 'I have the intention of $\mathrm{x}$ ', for ' $\mathrm{x}$ ' is considered a source of content. The content can be given by the external environment or by intrinsic properties (Lao and Deutsch, 2016). In not attending to the normative aspect of these expressions we also fail to acknowledge the normative aspect of other expressions such as 'Only I can feel my pain' is not privileged information about the supposed essential privacy of pain. 'Only I can feel my pain' is a means of stating the natural and logical condition of bodies (subjects). This means is given by the fact that it is a normative expression, not a descriptive one. 'I have the intention of $\mathrm{x}$ ' doesn't inform me of my intention (although it can inform others). It rather expresses my intentions. If we substitute ' $x$ ' for 'grabbing a coffee', 'grabbing a coffee' is not the content of my intention, but the expression of it. These uses of language are learnt by training. They show the way we conceive intentions, pain, bodies and ourselves. Eg. for 'intention' one is said to have the intention of grabbing a coffee when the following action is the attempt of grabbing a coffee, or when one thinks of it. The words we use to talk about feelings, sensations, intentions and so on, in the first person, such as: 'I feel', are instruments and they, in some ways, restrict what we can do with them (I can't use a mug to knit).

Therefore, private events are essentially private not because it is always true that they are private, rather, private events are private because this expression, namely, 'private events are essentially private' expresses our conception of private experiences. Our ways of talking about private experiences is normative (grammatical) and they express our conception of their nature:

What does it mean when we say, "I can't imagine the opposite of this" or "What would it be like if it were otherwise?" - For example, when someone has said that my mental images are private; or that only I myself can know whether I am feeling pain; and so forth. Of course, here "I can't imagine the opposite" doesn't mean: my powers of imagination are unequal to the task. We use these words to fend off something whose form produces the illusion of being an empirical proposition, but which is really a grammatical one (Wittgenstein, 2009, \$25I).

The idea that private experiences are always private is based on a distinction between private and public that is not applicable to 'private experiences' (we will come back to this point when considering explanations). If we do refer to private experiences by means of a dual picture private/public, it only emphasizes that the distinction doesn't apply to this case. Analogously, if we say that stones are always asleep, this is, in a way, always true, but it is also not a matter of truthfulness if there are no conditions for falsehood. In this sense, the consideration that stones always sleep is normative, not empirical. 
Similarly, for our experiences, it is not a matter of being public or private, since there are no conditions for falsehood of privacy.

Grammatical statements are normative. This means that they are not subject to truth conditions, rather to acceptance. They can become empiric statements once the agreement is set and also depending on the context (language game) in which they are used. Empiric statements, on the other hand, are subject to verification conditions and, giving that the conditions under which $\mathrm{A}$ is either true or false, provides in a great deal, means for understanding (for example, 'this is red'). Normative statements do not involve truth conditions, since what counts for their sense is not a matter of truth, but rather a matter of how we conceive (how we see) things (eg. 'human blood is red' or 'humans are mortal'). For example, 'this is red' is normative when one is pointing at red and teaching the color. 'This (or that) is red' is empirical when one can check whether the object is red or not; and this implies previous normative training of the use of 'red'. 'Blood is red' is normative for it also implies previous training and if is not a matter of truthfulness as much as 'stones are asleep'.

That said, the problem that it is not possible to investigate private mental states/events is not due to a supposed impossibility of empirical investigation of private/events, but to the point that private mental states and events are not to be defined according to empirical standards, but to public agreements. It is not a matter of truth, but of sense. Normative statements determine what makes sense to say instead of what is true.

In the case of private experiences, the normative character is given by the fact that the very experience is dropped out of consideration (Wittgenstein, 2009, \$293) if we conceive that the relation between private experiences and a name must have the private experience as a reference in the same way that we define objects ostensively (all language involving private experience is normative, not referential). First because private experiences cannot count as criteria for correctness and also because they are irrelevant for the meaning of the words, as we will see now with the private language argument and later with the beetle in the box analogy.

\section{The private language argument}

According to Wittgenstein, the reason why there can be no private language, is that the supposed private 'mental object', let us call it private experience, is dropped out of consideration if we conceive that the relation between private experiences and a name must have the private experience as a reference in the same way that objects count as reference when we define them ostensively (Wittgenstein, 2009, \$293), for the private experience cannot count as a criteria for correctness. For whatever seems to be correct, in this case, will be correct. This means that talking about correctness in this context is idle.

Here is Wittgenstein's example for the private language argument:

[...] I want to keep a diary about the recurrence of a certain sensation. To this end I associate it with the sign "s" and write this sign in a calendar for every day on which I have the sensation. - I first want to observe that a definition of the 
sign cannot be formulated. - But all the same, I can give one to myself as a kind of ostensive definition! - How? Can I point to the sensation? - Not in the ordinary sense. But I speak, or write the sign down, and at the same time I concentrate my attention on the sensation [...]. (Wittgenstein, 2009, \$258)

Why is it 'not in the ordinary sense' that I point to my sensation and define it ostensively? Because when I feel a sensation, or when a sensation happens in me, it doesn't have the object-like conditions of ascertainment that an object does. This is, when I concentrate my attention on the sensation, whatever I feel (or think I feel), is the sensation. If it seems (feels) the same, it is the same, if it seems (feels) different, it is different.

The fact that there are no ascertainment conditions for sensations as much as there are for objects doesn't mean that I cannot know what I am feeling or that I cannot know whether I am in pain. For feeling is not a matter of knowledge. One doesn't check its own feeling in order to know what it is. One can be told what the feeling is, but this also depends on external criteria. The fact that there are no ascertainment conditions for sensations also doesn't mean that I can't be mistaken about whether I feel hungry or of my stomach burns. I can be mistaken about this, as long as the criteria for correctness is public (external). This only means that whatever I feel (or what I think I feel) or see (if we assume that I might not know that I am hallucinating, for example) is what I feel, or see. There are no means for correction regarding my private experiences. If I think (or say) I dreamed that I saw a green sky, there is no possibility that I am mistaken about my dream and the sky was actually blue in my dream although I think it was green (I can of course dream that I have misperceived the sky in my dream, but this is not the point). The point is, again, whatever I see, whatever I feel, there is no other instance for correction.

Whatever is going to seem correct to me is correct. And that only means that here we can't talk about 'correct'. [...]. [For,] Looking up a table in the imagination is no more looking up a table than the image of the result of an imagined experiment is the result of an experiment (Wittgenstein, 2009, \$258; \$265).

This argument goes against content based theories of perception — such as Russell's sense data. If I had access to the content of my experiences, as opposed to just having experiences, I should be able to check if my experiences are what I think they are.

But, despite that, let us assume that private experiences are represented by neural activity, for the sake of the argument. "The question is, then, "How do words refer to sensations? - There doesn't seem to be any problem here; don't we talk about sensations every day, and name them? But how is the connection between the name and the thing named set up? [...]” (Wittgenstein, 2009, \$244).

I Ascertainment conditions can be understood as the possibility of verification that public objects have. 
Wittgenstein, in this passage, questions the referenciality of private experiences. For him, the question how words refer to sensations asks how we learn to use those words. In which situations and what actions count for one to say that it is nauseous, for example. For me to know what 'nauseous' means, someone, probably, has once asked me 'Are you nauseous?' when I was making that displeasing nauseous face. Or similarly, because someone told me: 'He is nauseous', when I was surprised about someone's strange nauseous behavior.

This question is the same as: How does a human being learn the meaning of names of sensations? For example, of the word "pain". Here is one possibility: words are connected with the primitive, natural, expressions of sensation and used in their place (Wittgenstein, 2009, \$244).

In other words, the answer to the idea that words refer (or cannot refer) to sensations is: not all language is representational. Linguistic representations, if we may say that they are representative, are given by training, not by reference. Assumed linguistic representations of private experiences are not representations, they are expressions. We will see this in more details below. Let us first consider the notion of representation more carefully.

\section{The notion of representation}

It is commonly accepted that smoke represents fire, that a map represents a city, that language represents thoughts, emotions and scenarios. Nevertheless, the reasons why these cases are called 'representation' differ in quality. The fire example is understood as representational with regards to causality. There is a causal association between fire and smoke that allows us to take that as a paradigmatic relation. Although not every time that there is fire we also have smoke and not every time that there is smoke there is also fire, we take smoke as representative of fire. This is due to the logically inductive aspect of a relation between natural events that we call causality. We have a reason to believe that where there is smoke, there is also fire.

The map example, on the other hand, displays an association based on rules of representation. This can be said to be the most fitting example of representation, for it displays clearly, the represented element, namely, the city, the very representation, namely, the map, and the conditions in which it represents, such as, the ratio, the position of the map and so on. (associative rules) Similarly, a graphic depicts. It represents to the extent that we establish a relation between its elements and the information we refer to. One knows how it represents when one is taught how to read the graphic. A picture (photograph or drawing) represents by its similarity to the represented element. In this case, the associative rules don't have to be shown or taught, for they are evident to the observers. Let us say, easily identifiable.

Linguistic representations are uses of language that we can call descriptions. Not all language is representational. Most of our use of language is, in fact, instrumental, not representational (see below). Language represents to the extent that a word stands for something else. 
The representation relation, or associative connection, as Wittgenstein says, is established by means of learning processes in which we grasp the uses of words. It requires training. "This ostensive teaching of words can be said to establish an associative connection between word and thing" (Wittgenstein, 2009, \$6). In other words, a name represents by means of training. For, the name stands for what is named due to an arbitrary associative trained correlation. We learn to use names to refer to things and we answer to the question of how we know that the name represents by recalling what we were taught. - How do you know that the name "apple" stands for the fruit apple? - Because we've learnt to use this word in such way.

Let's take a color name. According to Wittgenstein, we should consider a color sample as a standard by means of which we talk about colors. The sample is brought to language as a paradigm.

Suppose that samples of colour were preserved in Paris like the standard metre. So we explain that "sepia" means the colour of the standard sepia which is kept there hermetically sealed. Then it will make no sense to state of this sample either that it is of this colour or that it is not. We can put it like this: This sample is an instrument of the language, by means of which we make colour statements. In this game, it is not something that is represented, but is a means of representation (Wittgenstein, 2009, \$50).

In this context, the sample is neither red nor non-red. I.e. it is not subject to truth conditions. It is used to set what we understand as red. In other words, the sample is presented for the associative training. This is why he says that the sample is a means of representation. And it can be represented by other symbols, as a measuring tape can represent the standard meter in Paris; and the sample red can be represented by the name 'red'.

What Wittgenstein understands as a sample brought into language, we are calling a representative relation in which we consider the training as the means of representation between the name and the object or color. For, what is in question here is our capacity of learning the use of words from the sample, i.e., of associating the name with a sample.

The distinction that we mentioned before, between descriptive and instrumental uses of language, leads us to the non-representational role of language. Descriptive uses are also instrumental, but not all instrumental uses are descriptive. Words can be used for many different functions and they vary according to the situations in which they are used. "We do the most various things with our sentences. Think just of exclamations, with their completely different functions. Water! Away! Ow! Help! Splendid! No! Are you still inclined to call these words "names of objects"?" (Wittgenstein, 2009, \$27).

When it comes to thoughts and emotions, the representative role of language is certainly not in use. Language doesn't represent private experiences as it can represent a scene - once again, we are refusing of the object-name model of understanding private experiences. Language expresses thoughts and emotions. "One expresses what one thinks in behaviour, and most of what we think can be expressed only in linguistic (and other symbolic) behaviour" (Hacker, 2013, p. 386). 
Learning how to express private experiences in language also involves training, but this should not confuse us regarding the representationality of language. A sensation-name is not given in the same way that object-names are given. We express our sensations when we use sensation-words.

Expressing is not a relation. What is expressed (private experience) is not to be taken as an object that can be in a relation, for there are no ascertainment conditions for it, as we have seen in the private language argument.

Although we can express feelings in different ways and learn different ways of expressing them, we cannot say that expressing is a relation as much as representing. When we talk about linguistic expressions, the fact that we can be trained in different ways of communicating them, doesn't mean that there is an independent feeling that is going to be (arbitrarily) associated with the linguistic expression. But it also does not mean that the feeling changes according to different means of expression. For, as we will see below, it is not a matter of having something that is expressed. But of learning to substitute our natural dispositions for linguistic practices and frame our private experiences according to them.

A child has hurt himself and he cries; then adults talk to him and teach him exclamations and, later, sentences. They teach the child new pain-behaviour. "So you are saying that the word 'pain' really means crying?" - On the contrary: the verbal expression of pain replaces crying, it does not describe it (Wittgenstein, 2009, \$244).

Expressing a feeling is not necessarily communicating it. One can certainly cry for many kinds of pain, angst, grief, rage and better communicate them, as well as their reasons, using language. In this sense, communicating our feelings in language, other than merely expressing them, helps us to shape and define our feelings. To know what they are. Although merely expressing can also help when someone identifies our behavior (as nauseous example above). Communication involves understanding by others, while expression is an individual enterprise. An expression may or may not communicate.

Let us now come back to the notion of representation and to what justifies our conception of representation as a relation. The comparison between uses of 'representation' allows us to identify similarities in them. The three of them can be said to have (I) an element represented, (2) the one that represents and (3) the means of representation. In the fire example, the smoke represents fire by means of a paradigmatic causal relation. I.e. given that we observe smoke in a great number of cases of fire, and that we know that fire is one cause of smoke, we infer that there is fire when we see smoke. In the map example, the map represents the city by means of associative rules. I.e. one must learn how to read a map — what each of the symbols signify, what is the position that it must be read and how the space between the drawings of the buildings (or mountains) relates to the physical space represented. When reading a graphic, one must also know how each of the elements represents the information that can be expressed 
by other means. And in the language example, language represents the world by means of associative training. It is important to highlight that the representational account of language regards only its descriptive role. One learns how to use words and can describe a scene or a person based on what the words can refer to.

Saying that the associative training, the associative rules and the paradigmatic causal relation are the means of representation is justifiable by the fact that the three of them can be presented as an answer to the question 'How do you know that A represents B?'. 'How do you know that smoke represents fire?' - In this case, we mention the causal relation. 'How do you know that this map represents this city?' - Here we show the points of reference and how they refer (e.g. each $\mathrm{cm}$ is equivalent to one $\mathrm{km}$ ). How do you know that this linguistic description represents that scene? - Because this is how it looks like (we've learnt to describe these things is this way).

It is important to highlight that the question 'How do you know?' is neither asking for epistemic justification nor for conditions of knowledge, for we are not referring to cases of doubt or ignorance. For example, very roughly speaking, if I ask you, 'How do you know that there is a car in front of the house?', you might answer 'I can see it from the window'. This would be epistemic justification, because you are using the fact that you are currently perceiving something as justification for knowledge. If I ask you 'How do you know that the car is in front of the house', and you answer, 'Because I left it there yesterday', that would be an appeal to the conditions of knowledge, in this case, justified belief, not actual perception.

When it comes to private experiences, the question 'How do you know that you are in pain', is senseless. Being in pain is incompatible with doubting it (Hacker, 2005). For if one cannot know whether one is in pain, this means that one is not in pain.

It can't be said of me at all (except perhaps as a joke) that I know I'm in pain. What is it supposed to mean - except perhaps that I am in pain? Other people cannot be said to learn of my sensations only from my behaviour - for I cannot be said to learn of them. I have them. This much is true: it makes sense to say about other people that they doubt whether I am in pain; but not to say it about myself (Wittgenstein, 2009, \$246).

In cases in which one should present epistemic justification or conditions for knowledge the "concept of knowledge is bound up with the search for, grounds of or evidence for, and attainment of, truth, with the consequent possession and transmission of truths variously attained, and with reasons for thinking, feeling, acting and reacting" (Hacker, 2005, p. 207)

On the other hand, cases in which there is no justification possible, should be considered carefully and observed if the demand for justification is not due to the form of the question rather to the need of explanation. For "we sometimes demand explanations for the sake not of their content, but of their form" (Wittgenstein, 2009, \$217). 
"Once I have exhausted the justifications, I have reached bedrock, and my spade is turned. Then I am inclined to say: "This is simply what I do" (ibid.). The answer for 'How do you know you are in pain?' could be, 'I just feel it', probably accompanied by an expression of weirdness. And this is not a justification for knowledge, but merely an acknowledgment that no justification is needed.

So far, in this section, we presented the distinct uses of 'representation' and explained the reasons why they are taken to be representational, namely, (I) that they present the three elements of the relation: what is represented, the means of representation and the representation itself and (2) that the means of representation can be used as an answer to the question 'How do you know?' with non-epistemic values. We should briefly consider the implications of such distinct uses of representation. A representation by means of induction from causal relations will not be considered equal to a representation by means of associative training regarding the natural (causal) aspect. This is to say that the associative training does not involve the observation of natural phenomena as much as the induction from causal relations. The arbitrary aspect of language is not present in the causal case. Other than that, a linguistic description, for example, does not involve graphic elements and precision as a map does in order to guide. Ignoring that, would mislead us to the idea that language is somehow graphic or invoke graphic elements.

Thus, the problems of the use of 'representation' for understanding physical processes associated with mental processes, are the implications of such. One of these implications is the subsequent idea that a brain activity, for example, could hold semantic properties, such as content, truth-values and truth conditions. A representation, as we described above, is not an object with semantic properties, such as content, reference and truthvalues. A representation is an element of communication that depends on a relation. Private experiences cannot be taken to be one of the elements of a relation, for, as we have seen in the section about the private language argument, they do not hold consistent realization for ascertainment. This is, they cannot be taken as criteria for identity, for, whatever I remember my private experiences to be, this is what they are (Wittgenstein, 2009, \$258). Therefore, the question of how brain activity can represent is a question for the means of representation as opposed to a question for how to explain the mind in terms of the brain, or how can we connect the mind and the brain.

\section{Non-explanatory role of the concept of representation}

The context in which the problem of the ontological gap between the physical and the mental scopes is most prominent regards the idea that neural activity is representative of private mental states, events or properties. One of the most entangling questions is how the brain transforms sensory inputs into abstract mental representations. Mental representations are taken to be mental objects that have semantic properties, such as content, reference, truth-conditions and truth-values. In order to disentangle this problem, we have to observe what is the actual role of the notion of representation. 
The aim of this concept is to explain how the brain gives rise to abstract personal phenomena $^{2}$ (see e.g. Taylor, 20I2), which I call here 'private experiences'. Realists about mental representation take into account the explanatory role of representational content to defend that:

Mental representations are physical particulars that are realized in the brains (and maybe bodies) of thinkers and interact causally in virtue of non-semantic properties (e.g. "form"), in ways that are faithful to their semantic properties. Psychological processes like thinking, perceiving, reasoning and imagining then consist of causal processes taking place between representations with appropriate contents (Shea, 2013, p. 498).

Shea mentions that the notion of content plays an explanatory role in stating the realism of mental representations. Content is taken in this case, as a semantic property of the mental representation. Independently of how we understand the notion of content, either as a model for understanding brain functioning (e.g. Richmond et. al, 20I2) or as a description of real entities, it must be possible to establish the criteria under which we can identify and characterize it. Otherwise, the explanatory role gets defective, or empty.

Imagine a physiological explanation of the experience. Let it be this: When we look at the figure, our eyes scan it repeatedly, always following a particular path. The path corresponds to a particular pattern of oscillation of the eyeballs in looking [...]. Let this be the explanation. — "Yes, now I realize that it is a kind of seeing." [Following a path] — You have now introduced a new, a physiological, criterion for seeing. And this can conceal the old problem, but not solve it. - The purpose of this remark, however, was to bring out what happens when a physiological explanation is offered. The psychological concept hangs out of reach of this explanation. And this makes the nature of the problem clearer. (Wittgenstein, 2009, \$236, fragment) (my brackets)

In Wittgenstein's example, the physiological explanation of the visual experience involves identifying a new element (the eyeball path) and setting the criterion for ascertainment (the eyeball movements). We can, from the new element, its criterion, and the supposed regularity of its occurrence, take the physiological explanation of the event and consider it in a different way. In other words, to consider the visual experience according to different standards. This is the character of an explanation that doesn't work only as a metaphysical statement, or postulation.

Nevertheless, the psychological aspect of the experience, the private experience, remains untouched. As already suggested in the private language argument, the private

2 "In order to make progress on how the conscious mind is created by brain activity, we must also outline what it is we consider is the main structure of the mind. [...] consciousness can be seen to be divisible into I) Content. This is available for report and internal manipulation, being composed of the neural activities representing the colors, hardness and so on of objects, for example of the specific scent of the rose and the taste of the wine, and more generally of the various modality-based features of external objects in our consciousness; [...]" (Taylor, 20I2, p. 32). 
experiences are not subject to ascertainment conditions, for they are what they are according to public criteria. That is, they are determined by public practices and no introspection can provide criteria for their ascertainment.

In scientific explanations some theoretic elements can be postulated even if there are no observable criteria for ascertainment, such as atoms were assumed to be the smallest constituents of matter. What sets the difference for metaphysical postulations are the criteria for future identification. The atoms, for example, were thereafter observed and re-conceived.

Private experiences lack criteria for ascertainment and for future identification, for their nature is metaphysical. Their nature is given in language by how we use language and it is essentially non-referential.

The simple objects of the Tractatus are conceptually similar to the physical atoms. Wittgenstein's theory is, therefore, called logical atomism. In the Philosophical Investigations, Wittgenstein criticizes his own previous view (logical atomism) referring to the ideas of the Theaetetus about the primary elements as simples as much as Russell's individuals and his objects of the Tractatus (Wittgenstein, 2009, \$46). He develops this idea as opposed to something being composite in paragraphs 47 and 48:

But what are the simple constituent parts of which reality is composed? - What are the simple constituent parts of a chair? - The pieces of wood from which it is assembled? Or the molecules, or the atoms? - "Simple" means: not composite. And here the point is: in what sense 'composite'? It makes no sense at all to speak absolutely of the 'simple parts of a chair' (Wittgenstein, 2009, \$47).

He shows that whenever an explanation is taken as an explanation, it depends on whether we accept the rules that are implied in taking it as such. Namely, what we take as simple and composite in that case. The following quote gives an example of how different rules could be taken when we set up an explanation.

But isn't a chessboard, for instance, obviously, and absolutely composite? You're probably thinking of its being composed of 32 white and 32 black squares. But couldn't we also say, for instance, that it was composed of the colours black and white and the schema of squares? (Ibid.).

In this sense, what he is showing is that his explanation in the Tractatus (the logical atomism) lacks criteria for ascertainment (as much as our private experiences), for they hold on his assumption that there are logical simple objects, not on anything that can be considered as either simple or composite. This does not imply that there are no private experiences, as it implies that there are no simple objects. For the simple objects are a theoretical construct. Private experiences on the other hand, although not consistently realized, are not only a theoretical construct. But they do have the same status when it comes to determining whether they are simple or composite, or private or public.

But aren't our private experiences, obviously, and absolutely private? - We are probably thinking about epistemic privacy. — But couldn't we also say that people frequently 
do know how we feel? In what sense are our experiences private? It makes no sense to talk about an absolute privacy, for what we understand as private can be taken in several different ways. The Philosophical question is: Are our experiences private? And the answer is: That depends on what we understand as private. And this is not an answer, but a rejection of the question (ibid.).

A physical explanation of private experiences should present the element of investigation, its criterion, and the regularity of its occurrence. As the element of investigation, namely, the private experiences, is automatically out of the picture for it is not consistently realized. There can be no explanation of it. Therefore, the notion of representation, even if it aims to fulfill the ontological gap, cannot play this role. For, merely setting up a supposed connection is not sufficient for an explanatory role when the concepts of content and representation are keeping the conceptual problems that lead us to there, namely taking representation as an object with semantic properties and content as a property of this object.

\section{The "beetle in the box" analogy}

Let us now consider the beetle in the box analogy. The Wittgensteinian analogy with the beetle, as we will see in this section, shows that the private experiences (sensations, perceptions, private events and states) are irrelevant to the meaning of the words that we use to talk about them.

Suppose that everyone had a box with something in it which we call a "beetle". No one can ever look into anyone else's box, and everyone says he knows what a beetle is only by looking at his beetle. - Here it would be quite possible for everyone to have something different in his box. One might even imagine such a thing constantly changing. - But what if these people's word "beetle" had a use nonetheless? - If so, it would not be as the name of a thing. The thing in the box doesn't belong to the language-game at all; not even as a Something: for the box might even be empty. - No, one can 'divide through' by the thing in the box; it cancels out, whatever it is. That is to say, if we construe the grammar of the expression of sensation on the model of 'object and name', the object drops out of consideration as irrelevant (Wittgenstein, 2009, \$293).

In this analogy, the content of the box is hidden (logically, when it comes to private experiences) from any other person. In this way each person can only see the content of its own box. Although no one has ever seen the content of the box of the other, they refer to that content by means of the same word, namely, 'beetle' (or words, when it comes to sensations, or private events, or states).

Considering private experiences as irrelevant doesn't imply that they don't exist or that we don't know them, but merely that they are not a requirement for us to publicly use words and understand words that express them.

The natural impulse is the objection: one can learn to express pain without actually feeling it. Therefore, this would imply that they are not only irrelevant for our pain behavior but that we could also reduce them to nothing, says Wittgenstein's interlocutor: 
But you will surely admit that there is a difference between pain-behaviour with pain and pain-behaviour without pain." - Admit it? What greater difference could there be? - "And yet you again and again reach the conclusion that the sensation itself is a Nothing." - Not at all. It's not a Something, but not a Nothing either! The conclusion was only that a Nothing would render the same service as a Something about which nothing could be said. We've only rejected the grammar which tends to force itself on us here. The paradox disappears only if we make a radical break with the idea that language always functions in one way, always serves the same purpose: to convey thoughts — which may be about houses, pains, good and evil, or whatever (Wittgenstein, 2009, \$304).

That our private experiences are not something, but are not nothing either, means that they are not to be conceived in the object-name model. What is showed in this paragraph is that the way we conceive our private experiences (in the object-name model) plays a role in our understanding, and taking them either as something or as nothing doesn't change this role. Therefore, the object-name model provides no help to our understanding. ${ }^{3}$

But now we face the challenge of re-conceiving our private experiences. If they are not to be taken in the model of object and name, if they cannot be taken as something but also not as nothing, how should we even conceive them? Can we also, from this point, infer that the private experiences are irrelevant to our conceptions? - for what we understand as a beetle?

\section{Necessity of experiences for our conceptions}

Let us consider color blindness. Is it possible for red-green color blind people to understand what red is? One could answer that a color blind person understands that red is a color and that she cannot perceive it. In this sense, we would say that the color blind person does understand what red is and learns to associate the color red in many cases as much as we do, without actually having, and therefore considering, the private experience of red. Red in the traffic lights would, then, be identified by the position of the light. In strawberries, it could be distinguished by the softness and size of the fruit and so on.

In many cases, a public standard for distinction would simply be missing for that person and the fact that she doesn't perceive would imply that she cannot distinguish. She doesn't have the capacity and therefore the ability to distinguish. Capacities relate to our biological mechanisms, while the ability involves the training and learning processes that we engage in. ${ }^{4}$

3 The inner-outer duality is of the same kind. Private experiences are not in but it is not out either. This means that we should not take the inner world as opposed to the outer world. As we do when someone is out of a room or in the room, because there is no such thing as out, for private experiences. And, therefore, talking about the inner world cannot be a matter of truth, but only a normative expression (Nevertheless, it can be used to many different speech actions, to call attention to one self and so on).

4 Anthony Kenny takes the mind as "a capacity rather than an ability because it is a comprehensive ability to acquire abilities" (Kenny, 20IO, p. IO5) and commits to an infinite regress. He thereafter uses the notion of vehicles as the empirically necessary conditions for the exercise of the capacities. 
I argue that there is a normative distinction between capacities and abilities. One must have a capacity in order to develop, or be trained, into an ability. One can also improve one's capacity by developing abilities. For example, I am capable of knitting or crocheting, but I might not have learnt to do so, whereas a cat is not capable of doing this sort of hand work. The lion example in Wittgenstein's Philosophical Investigations shows clearly this distinction between capacities and abilities: 'if a lion could speak we wouldn't understand it' (Wittgenstein, 2009, \$327, fragment). For it is not only a matter of being capable of using words, but also what are the paradigms of use that we consider when using them and how we have learnt to do so. I.e, how we are trained to use words. If a lion were capable of using words, we would not understand him. For a lion to run at $80 \mathrm{~km} / \mathrm{h}$ after a prey is as natural as it is for me to grab a crochet needle. I.e. the concept of running for a lion (if lions could speak) would involve being able to catch a pray, it would involve failure or success in catching the pray, being hungry and satiated, maybe also playful with his babies and many other things that we may not even estimate. Imagine if a bat tells me, 'Take those fruits at the 'chirp chirp' position', where the 'chirp chirp' position is given by eco-location. I might not even be listening the third chirp! If a bat could speak, we wouldn't understand it. Unless we study their forms of life and have devices that capture sounds and light (and maybe many other things) in the same way they do.

Examples like these get highly refined when it comes to human forms of life, for we have very similar capacities and the distinctions are mostly due to different training, not necessarily due to different perceptual and acting capacities. If I say, for example, to my partner, 'Are you going to wear these wet shoes?' when he is about to wear his sneakers that were used in the rain in the night before, he might think that I'm concerned with possible damages to the wooden floor. In this case, I'm actually concerned that he is going to feel uncomfortable. My explanation for this, is that he has been trained to focus more on maintenance of goods and I've been trained to focus more on self-care.

To this extent we can say that it is not possible for the color blind person to use the word "red" in the same way that we do, for one very important paradigm of use is missing for her, due to the fact that she doesn't have the capacity for distinguishing and, therefore, doesn't develop the ability of mastering this concept in the same way non-color-blind people do. Using language and performing language-like expressions is a normative activity. We are trained to behave in certain ways (that may or may not convey information) and this training requires physical capacities. In this sense, the color-blind person does not understand the concept of red in the same way that we do.

Therefore, private experiences are not irrelevant for our conceptions. For they allow us to make distinctions and identify similarities. This only means that our capacities of seeing, hearing, feeling, thinking, talking and so on, are a condition for us to develop

5 Chirps are hight-pitched, short sounds. Bat sounds can be two times higher in pitch than humans are capable of listening. 
the abilities of distinguishing, speaking, understanding, following rules and so on. The character of our private experiences, on the other hand, are irrelevant given that we are able to perform these actions. E.g. making distinctions, speaking, calculating and so on). ${ }^{6}$

\section{Concluding remarks}

Why are we puzzled by the gap? The idea that there is an ontological gap between my private experiences and the physical process that may be responsible for them is provoked by several confusions of our understanding. These confusions are facilitated by our use of language, for it forces our thinking is a certain direction. Minding the role of our expressions may help to clarify these confusions. One of the distinctions that help to clarify them is presented by Wittgenstein between grammatical and empirical linguistic expressions. This distinction was introduced on the first section of this paper, the normative aspect of our expressions (section I).

Another source of misunderstandings is the notion of representation. Representation is mistakenly taken as an object with semantic properties as we have shown on section 3 . Besides that, when it comes to mental states, the representational relation is damaged, since the private experience can be neither the representative nor the represented element of the relation. Physical occurrences (such as brain activity) can be said to represent to the extent that there is a correlation between them and public events, such as what happens in our environment and expressions of private states. This correlation is what makes it possible to infer one from the other.

The notion of representation as it is used in cognitive neuroscience and theories of mind is one of the main points of confusion that lead us to the idea that there is an ontological gap between the mind and the brain. 'Representation' is taken to be a bridging term, but it carries the problem within its use, for, as we have seen, it involves a relation that it is overlooked when we take it as an object with semantic properties.

I also talk about the non-explanatory role that the concept of representation plays in the attempt of connecting the physical with the mental scope in section 4 . The failure of its explanatory role due to the very nature of representations exposed in section 3 is an important aspect for my suggestion that we should not take the physical and mental duality as forming an unbridgeable gap. For, it leads me to consider that perhaps nothing can bridge this assumed gap. Subsequently, I thought about the light analogy exposed below, which was - ironically — illuminating. But let us follow the items exposed in the text before we get there.

Wittgenstein's examples, namely the beetle in the box analogy (section 5) and the private language argument (section 2) tell us that whatever the character of our private

6 This might seem confusing because some capacities are also taken as abilities. I have the capacity and the ability of speaking, listening, paying attention and so on. But the fact that in many cases we cannot identify how capacities and abilities intertwine, does not undermine the normative distinction between them. 
experiences are, they are either not accountable as criteria or irrelevant for ascertainment. Therefore, reframing our traditional conception of what our private experiences are, namely, mental objects, is a central point when it comes to dissolving the gap. Finally, I clarify on section 6, that Wittgenstein's critique of the traditional views with his examples is not supposed to lead the reader to dismiss our private experiences. They are not to be taken in the object-name model, but they are fundamental to our existence.

Therefore, the six points of this text, namely, (I) the normative aspect of our expressions, (2) the private language argument, (3) representation as a relation (4) the non-explanatory role of the concept of representation, (5) the beetle in the box analogy, (6) experiences are necessary for our understanding/conceptions, sum up to give us a picture of how not to understand private experiences. Which is, mental states or events can't be in a relation with anything, which means that they are neither in a causal relation, nor in a representative relation.

But where does this lead us when it comes to understanding the mental scope and its relation to brain activity?

Regarding the nature of the correlation, namely, regarding the gap between a physical scope and a psychological/mental one, we can conceive that analogously to fire and its light. The light appears to us but it is neither caused by the fire, nor is it reduced to the fire, it is one aspect of the fire, one of the aspects of its ontology that we experience. This analogy points to the two aspects of experiences: the neural (biological) explanation and our private experiences. This does not mean that my private experiences appear to me as the light appears to us when there is fire. But simply, that we can understand the private experience and neural activity as two aspects of the same event. This picture avoids the reduction of the mind to the brain (Taylor, 2012), and also the need to explain the emergence of the mind from the natural events. For, both the duality and identity are maintained by the view that mind and brain are two aspects of one thing - which can be named as we wish.

In other words, the question of how the brain gives raise to the mind is equivalent to the question 'How does the fire provoke light?'. One answer can be given by its physico-chemical processes, and this will be an explanation that involves physico-chemical standards. It requires experiments and observation of regularities. It still leaves unanswered the question of how the fire, or the physico-chemical properties, give rise to the light. But this doesn't mean that we fail to provide an explanation, only that no explanation is needed.

\section{References}

Cash, M. (2009). "Normativity is the mother of intention: Wittgenstein, normative practices and neurological representations". In: New Ideas in Psychology, v. 27, Issue 2, pp. 133-I 47.

Hacker P. M. S. (2005). "Of knowledge and of knowing that someone is in pain". In: A. Pichler and S. Säätelä (eds.), Wittgenstein: The Philosopher and his Works. Bergen: The Wittgenstein Archives at the University of Bergen, pp. 203-235. 
(2013). The Intellectual Powers. A study of Human Nature. Oxford: Wiley-Blackwell.

Kenny, A. (2010). "Concepts Brain and Behavior". In: Grazer Philosophische Studies, v. 8I, pp. IOS-II3.

Lau, J., Deutsch, M. (20I6). “Externalism About Mental Content”. In: Edward N. Zalta (ed.) The Stanford Encyclopedia of Philosophy. Disponível em: https://plato.stanford.edu/archives/winzor6/entries/content-externalism/.

Nagel, T. (1974). "What Is It Like to Be a Bat?" In: The Philosophical Review, v. 83, n. 4, pp. 435-45O. DOI: I0.2307/2183914.

Richmond, S. D., Rees, G., Edwards, Sa. J. L. (20I2). I Know What You're Thinking: Brain imaging and mental privacy. Oxford Scholarship Online. DoI: Io.Io93/acprof:o so/9780199596492.001.00oI.

Shea, N. (2013). "Naturalising Representational Content". In: Philosophy Compass, 8(5), pp. 496-509.

TAYLOR, J. G. (2OI2). "A Final Solution to the Mind-Body Problem". In: Journal of Mind Theory, v. I, n. I, pp. 25-58.

Wittgenstein, L. (2009). Philosophical Investigations. Trad. G.E.M. Anscombe, P. M. S. Hacker and Joaquim Shulte. Oxford (UK): Wiley Blackwell [all references to this work show number of paragraphs]. 